\title{
COMMENTARY
}

\section{Post-conditioning: Promising answers and more questions}

\author{
David Bracco* \\ See related research by Steurer et al., http://ccforum.com/content/16/5/R191
}

\begin{abstract}
Volatile anesthetic agents have been used for decades in the peri-operative setting. Data from the past 15 years have shown that pre-injury administration of volatile anesthetic can decrease the impact of ischemia-reperfusion injury on the heart, brain, and kidney. Recent data demonstrated that volatile agents administered shortly after injury can decrease the ischemia-reperfusion injury. Several questions need to be answered to optimize this therapeutic target, but this is a promising era of secondary injury mitigation.
\end{abstract}

Cardiac anesthesia is associated with ischemia-reperfusion injury. Trying to limit the extent and mitigate the consequences of ischemia could potentially improve outcome after cardiac surgery. In the last 10 to 15 years, volatile agents have been shown to improve outcome in cardiac surgery. Despite these data, volatile anesthesia is not the most widely used technique for cardiac anesthesia. In the previous issue of Critical Care, Steurer and colleagues [1] presented interesting data on sevoflurane administration following cardiac surgery. These data have to be placed in the context of already-accumulated evidence and potential clinical applications.

Anesthetic gases are fascinating drugs: First-generation anesthetic gases, especially halothane, had significant cardiac side effects, increasing the risk of malignant arrhythmia and sensitizing the heart to catecholamines. Further generations, especially sevoflurane, have been shown to have interesting neuro- and cardioprotective properties. In the last 10 to 15 years, a wealth of data has shown that peri-operative administration of halogenated agents is associated with myocardial protection and better outcome.

*Correspondence: david.bracco@mcgill.ca

Montreal General Hospital, Room D10-145-3, 1650 Cedar Avenue, McGill University, Montreal, QC, H3G 1A4, Canada
Darwin proposed that species adapt to environment, the better-adapted breed having the better chances of survival. Interestingly, at the tissue, cell, mitochondrion, and possibly the gene level, there is a dynamic adaptation to the environment. This led to the concept of preconditioning, a mechanism in which brief sublethal periods of ischemia will provide protection from a subsequent lethal ischemia and mitigate the effect of ischemia-reperfusion [2]. As stated by Friedrich Nietzsche, 'What does not destroy me, makes me stronger. The organism or the tissue will acquire some 'injury-resistant' phenotype for a certain period of time [3]. Ischemic pre-conditioning is an interesting and powerful concept, but its clinical applicability is limited by the already-jeopardized myocardium.

All hypnotics decrease myocardial consumption and may favor the myocardial oxygen supply/demand balance. On top of these macrohemodynamic effects, halogenated agents have intrinsic cardio- and neuroprotective effects that are similar to those of ischemic pre-conditioning. At a basic science level, the myocardial protection effects of sevoflurane involve apoptotic mRNA inhibition, neuromodulation, cytokine/inflammation modulation, redoxsensitive pathways, endothelial preservation, ion channels, notch signaling pathways, and probably other mechanisms to be discovered. This translates clinically as a decrease in post-cardiac surgery troponin levels, lower inotropes requirements, and better cardiac output. Preconditioning is well established, and volatile agents are now recommended as the agent of choice by the American Heart Association for high-risk patients [4].

However, pre-conditioning is difficult to apply once the injury has already been established. Interestingly, brief periods of ischemia at the onset of the reperfusion period are associated with cardioprotection, leading to a myocardial infarction size decrease similar to [5] or slightly inferior to that of ischemic pre-conditioning [6]. Isoflurane has been shown to improve remodeling after coronary artery occlusion in rats [7]. In a similarly designed animal model of circulatory arrest published last year in this journal, sevoflurane administered immediately after the return of spontaneous circulation decreased myocardial 


\section{Table 1. Some research questions regarding sevoflurane post-conditioning}

Is the post-conditioning effect related to the "dose" of sevoflurane? Is there a minimum duration or minimum alveolar concentration to obtain post-conditioning? Is there a dose response curve on sevoflurane post-conditioning?

Do all volatile anesthetic agents (isoflurane or desflurane) provide the same post-conditioning organ protection?

Does the lower release in cardiac damage markers shown by Steurer et al. [1] translate into outcome differences? Lower myocardial infarction rates? Lower inotropic support? Better cardiac output? Shorter intensive care unit/hospital stays? Lower mortality? Lower resource utilization?

How long is the therapeutic window after reperfusion to exhibit a post-conditioning organ protection? That is, how long after cardiopulmonary bypass or injury does sevoflurane have to be started to induce post-conditioning?

Is there an additional cardioprotective effect when sevoflurane is used intraoperatively (pre-conditioning)?

Is there a protective effect on other organs such as the brain or the kidney?

Animal data suggest that post-conditioning is better in males [16] and inhibited by hyperglycemia [17]: Is post-conditioning beneficial only in males or in the context of tight glucose control (or both)?

Sevoflurane administration is associated with plasma fluoride levels above upper limit. How long can we use sevoflurane for sedation/post-conditioning in terms of fluoride toxicity?

damage [8]. The mechanisms of volatile agent postconditioning are being explored by several laboratories around the world $[9,10]$. Lemoine and colleagues [11] showed on in vitro right atrial appendages that the human heart is sensitive to desflurane-associated postconditioning. The data from Steurer and colleagues [1] offer the 'first in man' evidence of post-conditioning and potential myocardial protection in a clinical setting: sevoflurane administered in the intensive care unit (ICU) arrival for 4 hours. They showed a decreased troponin release in the sevoflurane group. Interestingly, there was still an effect even with a 2- to 3-hour gap after the onset of ischemia (aortic clamping) and a 1- to 2-hour gap between the start of reperfusion (aortic cross-clamp release) and the administration of sevoflurane (upon arrival to the ICU). This investigation opens a new field and new potential therapeutic opportunities. Further questions remain to be answered to optimize and assess the clinical magnitude of myocardial protection provided by post-conditioning (Table 1 ).

Sevoflurane and isoflurane are very flexible generic anesthetic drugs administered daily by numerous anesthetists around the world. The demonstration of cardioor neuroprotective effects (or both) when applied after the ischemia will make them interesting in myocardial ischemia, cardiogenic shock, or even traumatic brain injuries. Sevoflurane administration in the ICU has been done previously [12,13]. It has been shown to be associated with fast awakening/weaning times after the drug is stopped [12]. The anesthesia-conserving device has made the delivery simple and adaptable on 'regular' ICU-type ventilators. However, technical aspects such as gas analyzers, concentration measurement, and exhausted gas scavenging (most ICU-type ventilators release the exhaust gases into the environment) need to be taken into account. Educational aspects must include nurse training, dosage, availability of dantrolene, and training for the unlikely event of a malignant hyperthermia reaction. In addition, data show plasma fluoride concentration $(39 \pm 25 \mu \mathrm{mol} / \mathrm{L})$ close to safety limits $(50 \mu \mathrm{mol} / \mathrm{L})$ at 24 and 48 hours after 9 hours of sevoflurane [14]. Sevoflurane administration beyond 12 to 24 hours needs to be assessed in terms of fluoride plasma concentration and nephrotoxicity. Environmental effects of widespread anesthetic gas use need to be taken into account [15]. Most cardiac surgery patients require a maximum of a few hours of mechanical ventilation (if any). In these circumstances, sevoflurane sedation in the cardiac ICU may be a very flexible option with an additional myocardial protection benefit.

\section{Conclusions}

Sevoflurane and possibly other volatile anesthetic agents show promising post-conditioning properties after cardiac surgery. This opens a new field of investigations and potential therapies aiming at mitigating secondary myocardial injury after the primary injury is done. More data are necessary to assess the magnitude conferred by this protection, its clinical relevance, the window of opportunity, and the collateral protection on other organs. Very promising answers, and more questions, are to come.

\section{Abbreviation}

ICU, intensive care unit.

\section{Competing interests}

The author declares that he has no competing interests.

Published: 23 November 2012

\section{References}

1. Steurer MP, Steurer MA, Baulig W, Piegeler T, Schläpfer M, Spahn DR, FalkV, Dreessen P, Theusinge OM, Schmid ER, Schwartz D, Neff TA, Beck-Schimmer B: Late pharmacological conditioning with volatile anaesthetics after cardiac surgery. Crit Care 2012, 16:R191.

2. Murry CE, Jennings RB, Reimer KA: Preconditioning with ischemia: a delay of lethal cell injury in ischemic myocardium. Circulation 1986, 74:1 124-1136.

3. Gidday JM: Cerebral preconditioning and ischaemic tolerance. Nat Rev Neurosci 2006, 7:437-448 
4. Fleisher LA, Beckman JA, Brown KA, Calkins H, Chaikof EL, Fleischmann KE, Freeman WK, Froehlich JB, Kasper EK, Kersten JR, Riegel B, Robb JF, Smith SC Jr., Jacobs AK, Adams CD, Anderson JL, Antman EM, Buller CE, Creager MA, Ettinger SM, Faxon DP, Fuster V, Halperin JL, Hiratzka LF, Hunt SA, Lytle BW, Nishimura R, Ornato JP, Page RL, Riegel B, Tarkington LG, Yancy CW: ACC/AHA 2007 Guidelines on Perioperative Cardiovascular Evaluation and Care for Noncardiac Surgery: Executive Summary: A Report of the American College of Cardiology/American Heart Association Task Force on Practice Guidelines (Writing Committee to Revise the 2002 Guidelines on Perioperative Cardiovascular Evaluation for Noncardiac Surgery) Developed in Collaboration With the American Society of Echocardiography, American Society of Nuclear Cardiology, Heart Rhythm Society, Society of Cardiovascular Anesthesiologists, Society for Cardiovascular Angiography and Interventions, Society for Vascular Medicine and Biology, and Society for Vascular Surgery. J Am Coll Cardiol 2007, 50:1707-1732.

5. Zhao ZQ, Corvera JS, Halkos ME, Kerendi F, Wang NP, Guyton RA, VintenJohansen J: Inhibition of myocardial injury by ischemic postconditioning during reperfusion: comparison with ischemic preconditioning. Am J Physiol Heart Circ Physiol 2003, 285:H579-588.

6. Kin H, Zhao ZQ, Sun HY, Wang NP, Corvera JS, Halkos ME, Kerendi F, Guyton RA, Vinten-Johansen J: Postconditioning attenuates myocardial ischemiareperfusion injury by inhibiting events in the early minutes of reperfusion. Cardiovasc Res 2004, 62:74-85.

7. Feng J, Fischer G, Lucchinetti E, Zhu M, Bestmann L, Jegger D, Arras M, Pasch T, Perriard JC, Schaub MC, Zaugg M: Infarct-remodeled myocardium is receptive to protection by isoflurane postconditioning: role of protein kinase B/Akt signaling. Anesthesiology 2006, 104:1004-1014.

8. Meybohm P, Gruenewald M, Albrecht M, Müller C, Zitta K, Foesel N, Maracke M, Tacke S, Schrezenmeir J, Scholz J, Bein B: Pharmacological postconditioning with sevoflurane after cardiopulmonary resuscitation reduces myocardial dysfunction. Crit Care 2011, 15:R241.

9. Feng J, Lucchinetti E, Ahuja P, Pasch T, Perriard JC, Zaugg M: Isoflurane postconditioning prevents opening of the mitochondrial permeability transition pore through inhibition of glycogen synthase kinase 3beta. Anesthesiology 2005, 103:987-995
10. Yu LN, Yu J, Zhang FJ, Yang MJ, Ding TT, Wang JK, He W, Fang T, Chen G, Yan M: Sevoflurane postconditioning reduces myocardial reperfusion injury in rat isolated hearts via activation of PI3K/Akt signaling and modulation of Bcl-2 family proteins. J Zhejiang Univ Sci B 2010, 11:661-672.

11. Lemoine S, Beauchef $G$, Zhu L, Renard E, Lepage O, Massetti M, Khayat A, Galera P, Gerard JL, Hanouz JL: Signaling pathways involved in desfluraneinduced postconditioning in human atrial myocardium in vitro. Anesthesiology 2008, 109:1036-1044.

12. Mesnil M, Capdevila X, Bringuier S, Trine PO, Falquet Y, Charbit J, Roustan JP, Chanques $\mathrm{G}$, Jaber $\mathrm{S}$ : Long-term sedation in intensive care unit: a randomized comparison between inhaled sevoflurane and intravenous propofol or midazolam. Intensive Care Med 2011, 37:933-941.

13. Pratt PF Jr., Wang C, Weihrauch D, Bienengraeber MW, Kersten JR, Pagel PS, Warltier DC: Cardioprotection by volatile anesthetics: new applications for old drugs? Curr Opin Anaesthesiol 2006, 19:397-403.

14. Rohm KD, Mengistu A, Boldt J, Mayer J, Beck G, Piper SN: Renal integrity in sevoflurane sedation in the intensive care unit with the anestheticconserving device: a comparison with intravenous propofol sedation. Anesth Analg 2009, 108:1848-1854

15. Sulbaek Andersen MP, Sander SP, Nielsen OJ, Wagner DS, Sanford TJ Jr. Wallington TJ: Inhalation anaesthetics and climate change. Br J Anaesth 2010, 105:760-766

16. Zheng Z, Yang M, Zhang F, Yu J, Wang J, Ma L, Zhong Y, Qian L, Chen G, Yu L, Yan M: Gender-related difference of sevoflurane postconditioning in isolated rat hearts: focus on phosphatidylinositol-3-kinase/Akt signaling. J Surg Res 2011, 170:e3-9.

17. Inamura Y, Miyamae M, Sugioka S, Domae N, Kotani J: Sevoflurane postconditioning prevents activation of caspase 3 and 9 through antiapoptotic signaling after myocardial ischemia-reperfusion. J Anesth 2010, 24:215-224.

doi:10.1186/cc11850

Cite this article as: Bracco D: Post-conditioning: Promising answers and more questions. Critical Care 2012, 16:180. 